\title{
A case study on numerical simulation of a historical masonry building
}

\author{
Embiya Tilki ${ }^{1}$ (D), Arif Velioğlu ${ }^{1}$ (D), Barış Sayın ${ }^{* 2}$ (D) \\ ${ }^{1}$ Istanbul University-Cerrahpaşa, Institute of Graduate Studies in Science and Engineering, Istanbul, \\ Turkey \\ ${ }^{2}$ Istanbul University-Cerrahpaşa, Department of Civil Engineering, Istanbul, Turkey
}

\begin{abstract}
Masonry buildings are ordinarily complex construction systems and there is a lack of knowledge and information concerning the behavior of their seismic response. Due to the life safety of masonry buildings under seismic effects are very essential, numerical modeling and analysis of the buildings are an important issue. Because of the insufficient seismic resistance on structural members such as jack arch slabs and masonry walls, numerical studies have become necessary to determine the level of the structural strength of the structures. The tensile strength of load-bearing walls in the buildings is lower whereas, the compressive strength is higher. In this way, tensile cracks occur at structural members due to insufficient tensile resistance. Therefore, the tensile stress locations in the structure are critical. The study focuses on the assessment of historical masonry buildings from the point of seismic resistance. The entire process is performed using a case study from a historical masonry building. In this study conducted in this respect, the existing situation of a historical building using numerical analyses were presented with the cross-disciplinary study of civil engineering and architecture. The linear elastic analysis is selected as an analysis method. The seismic parameters are determined based on the Turkish Earthquake Code (TBEC 2018). Consequently, the study is performed to determine the seismic-resistant of historical buildings within the scope of numerical analyses.
\end{abstract}

\section{Keywords}

Masonry buildings; Seismic effect; Earthquake code; Linear elastic analysis

Received: 19 September 2019; Accepted: 17 September 2020

ISSN: 2630-5763 (online) C 2020 Golden Light Publishing All rights reserved.

\section{Introduction}

The land of our country is home to many civilizations and is rich in architectural works. A very large part of the historical buildings was built with the masonry building technique. This technique has been used throughout the history of mankind and is still used today. The masonry structures are horizontal and vertical load-bearing structures with the walls formed by an artificial or natural brick/stone bonding mortar. The structures are preferred because they can be constructed easily and cost-effectively with natural materials in the region. functions. The walls forming the space volumes also protect the structure from external factors. On the other hand, masonry structures lack ductile behavior. While it is expected that the possible damage to the earthquake is to a minimum, it is very complicated and difficult to provide this necessity. On the other hand, providing ductile behavior may disrupt the original character of historic buildings. The behavior characteristics of masonry structures under the effect of dynamic

\footnotetext{
Corresponding author

Email: barsayin@istanbul.edu.tr
} 
loads are different from the properties of concrete and steel. Besides, the analysis of seismic behavior is complicated by the fact that the load-bearing elements are composed of local materials with different characteristics. The parameters used in the analysis and the determination of the characteristics of the materials are important for the correct determination of the structural behavior. The most important detail that should be considered in the repair and strengthening of the masonry structures with insufficient seismic resistance is the fact that the structure is not disturbed and the intervention is kept to a minimum. In addition to ensuring the security of the structure, the historical authenticity of the building must be preserved.

Strengthening is the intervention to increase the load-bearing capacity, rigidity, ductility, and performance level of a structure above the existing structural strength level or to bring the carrier elements of a damaged structure to a level that is better than the pre-damage situation. If the masonry structures damaged by the earthquake are only repaired, they are likely to be damaged again in an earthquake that may be exposed during their service life. Furthermore, it is not essential the structure must be damaged for strengthening. The loadcarrying capacity of the structure may not meet the requirements of the specification without damaging the structure. In such cases, strengthening is mandatory and various methods and techniques are preferred. This study includes modeling of the basement, ground, and two normal stories by using the SAP2000 software [1] model and a time history analysis using the architecture plan (Fig. 1). Design parameters are obtained as a reference from TBDY 2018 [2]. Within the scope of the study, after the analysis of the structure has been performed, strengthening proposals are also presented.

\section{Numerical modeling}

The structure, having $19 \mathrm{~m}$ height and a $244 \mathrm{~m} 2$ residing area, was built as a basement, ground, two normal, and the roof stories. Numerical analysis of the masonry structure was done by linear elastic approach.

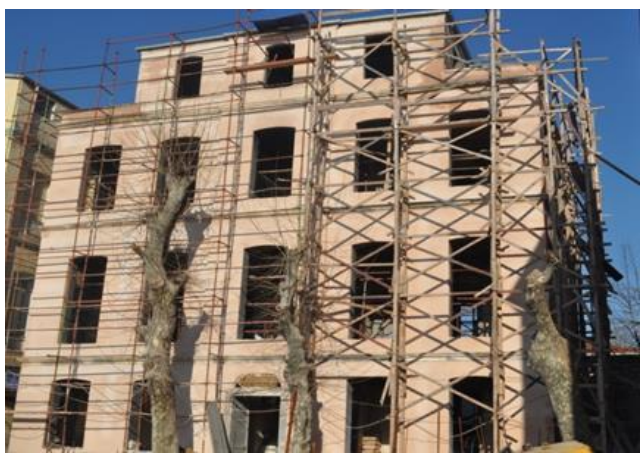

Fig. 1. The facade view of the building (İstanbul Üniversitesi, Eski Devlet Arşivleri, Blok B)

The basic and ground floor plans of the said structure are shown in Fig. 2. In the numerical model prepared with SAP2000 software, the interior walls are considered as $43 \mathrm{~cm}$, the facade walls are $56 \mathrm{~cm}$ and the floorings are $35 \mathrm{~cm}$ thick. All the parameters of the design are taken from TBDY 2018 and the material properties are given in Table 1 and the design parameters are given in Table 2. As a modeling method, macro modeling was preferred by the finite element method. In macro modeling, the unit and mortar are considered as a composite material instead of being modeled separately [3]. However, in the analysis using the finite element method; it can be modeled using detailed micro modeling, simplified micro modeling, or macro modeling techniques (TBEC 2018). The shell element is used for the finite element modeling. Thin plate theory (Kirchhoff's Theory) and Reissner - Mindlin Plate theory are used in the shell element formulation. There are studies in the literature using different solution methods based on Reissner and Mindlin's theories [4-8]. A thick plate formulation was chosen in this study. As the walls are perpendicular to the plane and the doorway and window openings are critical in terms of strength, in these parts, in-plane and outof-plane shear stresses are important. In the analyzes, earthquake loads were applied in $x$ and $y$ directions. Spectral acceleration graphs are obtained based on the parameters in Table 4 and then time history analysis is performed. Nine load combinations were prepared for analysis and the most unfavorable loadings were taken into account (Table 3). 


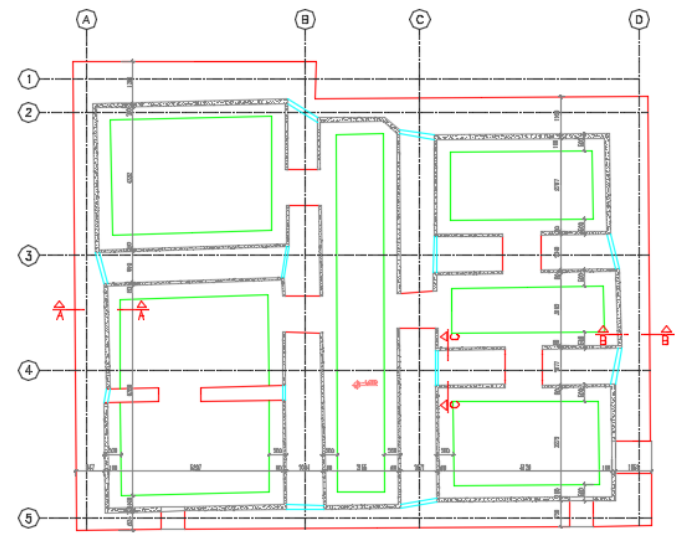

(a) Foundation plan

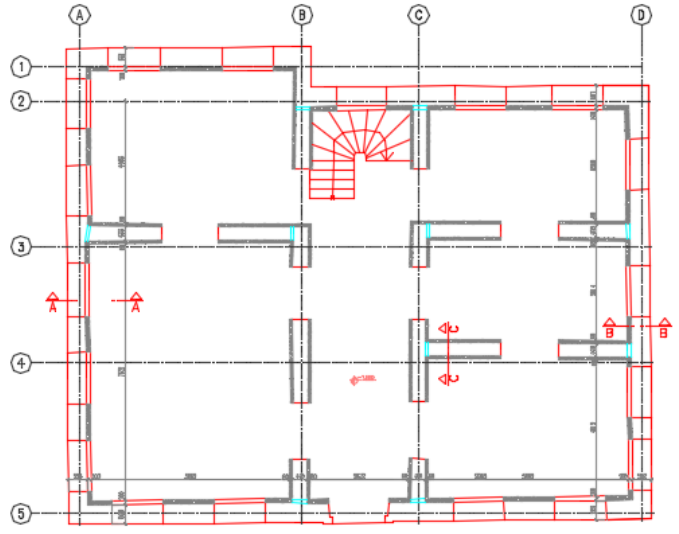

(b) Ground story plan

Fig. 2. The basic and ground floor plans of the structure

Table 1. Material properties

\begin{tabular}{lccc}
\hline Member & Density $\left(\mathrm{kN} / \mathrm{m}^{3}\right)$ & Elasticity modulus $(\mathrm{MPa})$ & Poission ratio \\
\hline Wall & 20 & 2400 & 0.2 \\
Slab & 20 & 2500 & 0.2 \\
Foundation & 25 & 30000 & 0.2 \\
\hline
\end{tabular}

Table 2. Analysis parameters

\begin{tabular}{lc}
\hline Parameter & Value \\
\hline Effective ground acceleration coefficient $\left(\mathrm{A}_{\mathrm{o}}\right)$ & 0.40 \\
Building importance factor $(\mathrm{I})$ & 1.4 \\
Seismic load reduction factor $\left(\mathrm{R}_{\mathrm{x}} / \mathrm{R}_{\mathrm{y}}\right)$ & 2 \\
Spectrum coefficient, $\mathrm{S}_{\mathrm{t}}$ & 2.5 \\
\hline
\end{tabular}

Table 3. Loading combinations

\begin{tabular}{ll}
\hline Combination & Value \\
\hline COMB 1 & $1.0 \mathrm{G}+1.0 \mathrm{Q}$ \\
COMB 2 & $1.0 \mathrm{G}+1.0 \mathrm{Q}+1.0 \mathrm{EX}+0.3 \mathrm{EY}$ \\
COMB 3 & $1.0 \mathrm{G}+1.0 \mathrm{Q}+1.0 \mathrm{EX}-0.3 \mathrm{EY}$ \\
COMB 4 & $1.0 \mathrm{G}+1.0 \mathrm{Q}-1.0 \mathrm{EX}+0.3 \mathrm{EY}$ \\
COMB 5 & $1.0 \mathrm{G}+1.0 \mathrm{Q}-1.0 \mathrm{EX}+0.3 \mathrm{EY}$ \\
COMB 6 & $1.0 \mathrm{G}+1.0 \mathrm{Q}-1.0 \mathrm{EX}+0.3 \mathrm{EY}$ \\
COMB 7 & $1.0 \mathrm{G}+1.0 \mathrm{Q}+1.0 \mathrm{EY}+0.3 \mathrm{EX}$ \\
\hline
\end{tabular}

\section{Analysis results}

The 3D numerical model prepared for analysis is shown in Fig. 3. The period values obtained in the time history analysis are given in Table 4. Fig. 4 shows the stress density around the doorway and window openings. Fig. 5 shows the stresses on the facades. Especially in the first and second-floor windows on the facades, the force and displacement values have higher values. In general, structures are deformed after the earthquake. Earthquake motion on the ground, trying to pull the building towards one side, the structure with the weight of this movement against the movement of the structure to be reinstated. 


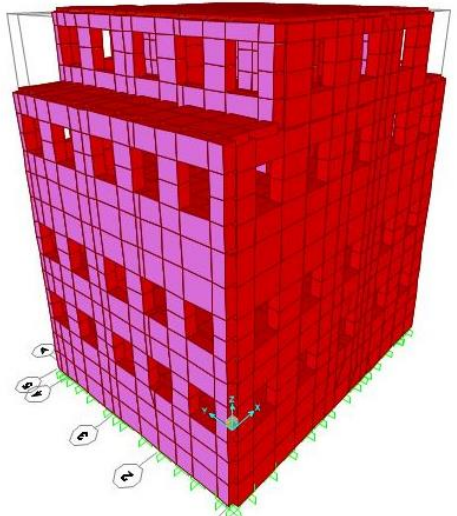

Fig. 3. 3D numerical model of the building

Table 4. Period and acceleration values obtained in time history analysis

\begin{tabular}{|c|c|c|c|c|c|c|}
\hline Output case & Step number & Period (Sec) & $\mathrm{U} 1 \mathrm{Acc}\left(\mathrm{m} / \mathrm{sec}^{2}\right)$ & U2Acc $\left(\mathrm{m} / \mathrm{sec}^{2}\right)$ & U1Amp (m) & U2Amp (m) \\
\hline EX & 1 & 1.15 & 0.30 & 0 & -0.038 & 0 \\
\hline EX & 2 & 0.90 & 0.36 & 0 & -0.28 & 0 \\
\hline EX & 3 & 0.59 & 0.50 & 0 & 0.005 & 0 \\
\hline EX & 4 & 0.39 & 0.7 & 0 & 0.003 & 0 \\
\hline EX & 5 & 0.33 & 0.7 & 0 & 0.019 & 0 \\
\hline EX & 6 & 0.31 & 0.7 & 0 & 0.019 & 0 \\
\hline EX & 7 & 0.29 & 0.7 & 0 & 0.0003 & 0 \\
\hline EX & 8 & 0.28 & 0.7 & 0 & 0.003 & 0 \\
\hline EX & 9 & 0.27 & 0.7 & 0 & -0.001 & 0 \\
\hline EX & 10 & 0.26 & 0.7 & 0 & -0.004 & 0 \\
\hline EX & 11 & 0.26 & 0.7 & 0 & 0.003 & 0 \\
\hline EX & 12 & 0.26 & 0.7 & 0 & 0.003 & 0 \\
\hline EY & 1 & 1.15 & 0 & 0.30 & 0 & -0.39 \\
\hline $\mathrm{EY}$ & 2 & 0.90 & 0 & 0.36 & 0 & 0.029 \\
\hline $\mathrm{EY}$ & 3 & 0.59 & 0 & 0.50 & 0 & 0.006 \\
\hline $\mathrm{EY}$ & 4 & 0.39 & 0 & 0.7 & 0 & 0.04 \\
\hline $\mathrm{EY}$ & 5 & 0.33 & 0 & 0.7 & 0 & -0.006 \\
\hline $\mathrm{EY}$ & 6 & 0.31 & 0 & 0.7 & 0 & 0.003 \\
\hline EY & 7 & 0.29 & 0 & 0.7 & 0 & 0.0008 \\
\hline $\mathrm{EY}$ & 8 & 0.28 & 0 & 0.7 & 0 & -0.001 \\
\hline EY & 9 & 0.27 & 0 & 0.7 & 0 & 0.0004 \\
\hline EY & 10 & 0.26 & 0 & 0.7 & 0 & 0.004 \\
\hline EY & 11 & 0.26 & 0 & 0.7 & 0 & 0.002 \\
\hline $\mathrm{EY}$ & 12 & 0.26 & 0 & 0.7 & 0 & 0.0004 \\
\hline
\end{tabular}




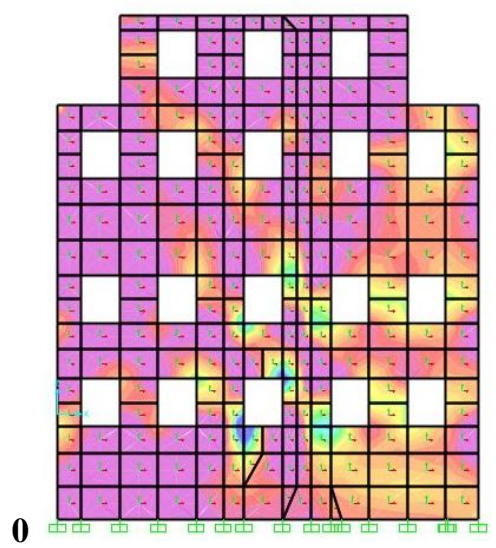

(a)

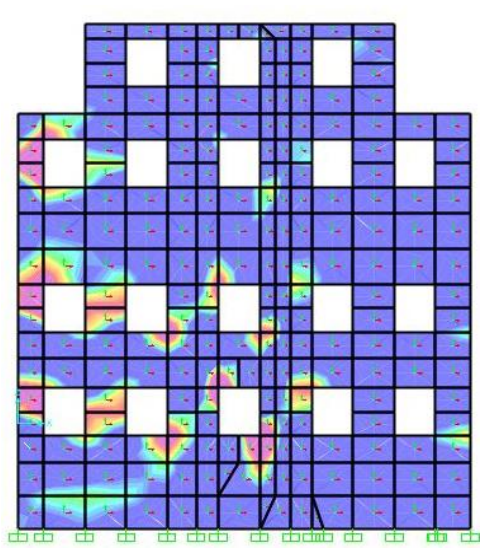

(c)

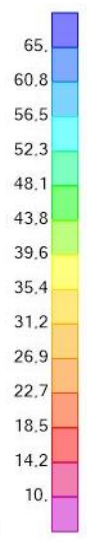

-50.
-53.1
-56.2
-59.2
-62.3
-65.4
-68.5
-71.5
-74.6
-77.7
-80.8
-83.8
-86.9
-90.
-

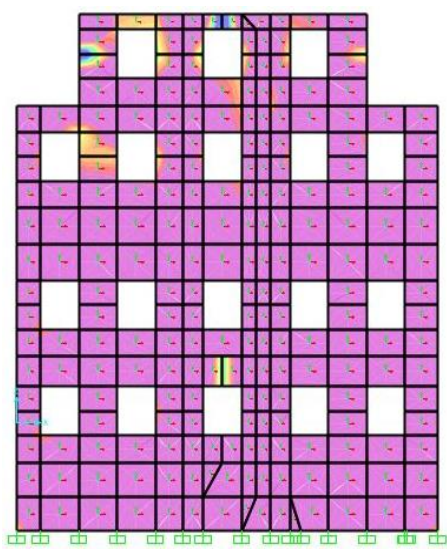

(d)

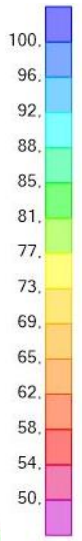

(b)

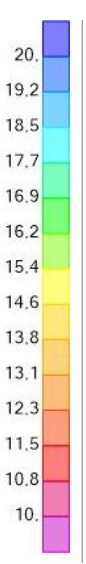

Fig. 4. (a) Maximum force distribution, F12, (b) Maximum stress distribution, S12, (c) Minimum stress distribution, S12, (d) Maximum force distribution, V23
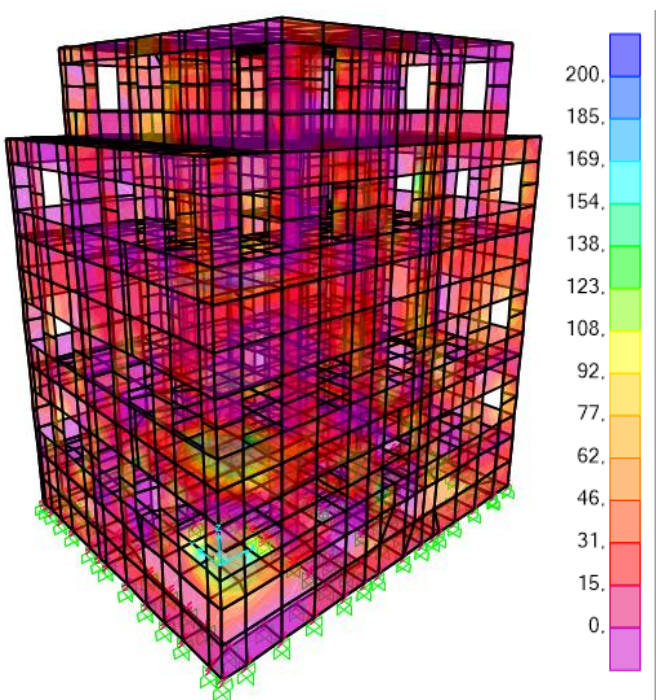

Fig. 5. Stresses provided in the facades 
In this case, the structure shows the behavior of moving left and right. The structural elements are not damaged in the regions with sufficient resistance between the elements that make up the structure. However, damage or cracks may occur due to high stress and load deformations in unresolved areas.

\section{Conclusions}

It is necessary to determine possible structural damages that may occur in the masonry structures and to take structural preventions in this way. Even if it is not damaged, it is necessary to strengthen the masonry structures which do not have sufficient strength and seismic safety according to the current codes. In this scope, different strengthening techniques are used in masonry structures. Numerical analysis of the masonry structure was carried out.

As a result of the analyzes performed, high stresses and internal forces were obtained on the first and second-floor facade walls, various doorway and window openings, and on the attic walls. Rehabilitation works should be performed on these regions due to the prediction of deformations as well as in-plane and out-of-plane cracks. The strengthening applications may be (i) slab strengthening, (ii) mesh rebar, spraying concrete, carbon FRP in inner walls, (iii) carbon fiber plate and wrap in horizontal $x$-form along with the floor level due to the stress density around window opening in the facade, and (iv) placing a steel plate on the edge surfaces of the doorway and window opening, which are the tensile density in the structure.

\section{Declaration of conflicting interests}

The author(s) declared no potential conflicts of interest concerning the research, authorship, and/or publication of this article.

\section{References}

[1] SAP2000 (2018) Structural Software for Analysis and Design. v.18. Computers Structures Inc. Berkeley, USA.
[2] TBEC (2018) Turkey Building Earthquake Code: Rules for design of buildings under earthquake effect. Official Gazzette 18.03.2018, 30364.

[3] Lourenço PB (1996) Computational Strategies for Masonry Structures. Ph.D Thesis. Delft University of Technology, The Netherlands.

[4] Mindlin RD (1951) Influence of rotatory inertia and shear on flexural motions of isotropic elastic plates. Journal of Applied Mechanics 18: 31-38.

[5] Reissner E (1945) The effect of transverse shear deformation on the bending of elastic plates. Journal of Applied Mechanics 67: 69-77.

[6] Michell JH (1899) On the direct determination of stress in an elastic solid with application of the theory plates. Proceedings of the London Mathematical Society 31: 100-124.

[7] Szilard R (1974) Theory and Analysis of Plates. Prentice-Hall Inc.

[8] Chonan S (1980) Random vibration of an initially stressed thick plate on an elastic foundation. Journal of Sound and Vibration 71(1): 117-127. 